\title{
Halfway up the trophic chain: development of parasite communities in the sparid fish Boops boops
}

\author{
A. PÉREZ-DEL OLMO ${ }^{1,2 *}$, M. FERNÁNDEZ ${ }^{1}$, J. A. RAGA ${ }^{1}$, A. KOSTADINOVA ${ }^{1,3}$ \\ and $\mathrm{R}$. POULIN ${ }^{2}$ \\ ${ }^{1}$ Marine Zoology Unit, Cavanilles Institute of Biodiversity and Evolutionary Biology, University of Valencia, \\ PO Box 22085, 46071 Valencia, Spain \\ ${ }^{2}$ Department of Zoology, University of Otago, P.O. Box 56, Dunedin, New Zealand \\ ${ }^{3}$ Central Laboratory of General Ecology, Bulgarian Academy of Sciences, 2 Gagarin Street, 1113 Sofia, Bulgaria
}

(Received 20 Fuly 2007; revised 29 Fuly 2007; accepted 30 Fuly 2007; first published online 2 October 2007)

\begin{abstract}
SUMMARY
We examined the patterns of composition and structure of parasite communities in the Mediterranean sparid fish Boops boops along a gradient of fish sizes, using a large sample from a single population. We tested the hypothesis that species forming the core of the bogue parasite fauna (i.e. species which have a wide geographical range and are responsible for recognizable community structure) appear early in the fish ontogeny. The sequential community development observed supported the prediction that core species appear in the fish population earlier than rare and stochastic species. There was also a strong correlation between the order of 'arrival' of the species and their overall prevalence. Six key species were responsible for recognizable community structure across size/age cohorts; the addition to this baseline community of key parasite species resulted in a nested structure that is linked to differential species abundance rather than fish size. Information on the life-cycles, distribution and host range of the parasites is used to explain the observed patterns of parasite community structure. We conclude that the small mouth size of $B$. boops coupled with suction feeding may provide a setting for passive sampling as a mechanism leading to non-random parasite community structure.
\end{abstract}

Key words: Boops boops, Sparidae, Mediterranean, parasites, community development, nested structure.

\section{INTRODUCTION}

Although the idea that infection by metazoan parasites increases with age in fish hosts is not new (see Dogiel et al. 1958), recent empirical evidence suggests that a wide range of host traits, such as body size and/or age (e.g. Guégan and Hugueny, 1994; Lo et al. 1998; Vidal-Martinez et al. 1998; Poulin, 2000; Johnson et al. 2004), habitat and diet (e.g. trophic status, feeding rates; Sasal et al. 1999; Muñoz et al. 2006), degree of vagility (Kennedy, 1990), social behaviour and schooling (Bartoli et al. 2000; Luque et al. 2004) act jointly to provide structure to fish parasite communities. However, studies at the host population level are necessary to pinpoint the role of host age per se, and these are still few.

Nested subset analyses have proved a useful analytical tool to detect size/age-associated compositional heterogeneity across fish parasite assemblages (Guégan and Hugueny, 1994; Poulin and Valtonen, 2001; Timi and Poulin, 2003). An ontogenetic shift in host diet and/or habitat utilization

* Corresponding author: Marine Zoology Unit, Cavanilles Institute of Biodiversity and Evolutionary Biology, University of Valencia, PO Box 22085, 46071 Valencia, Spain. Tel: +34 963543657. Fax: +34 963543733. E-mail: ana.perez-olmo@uv.es is a straightforward mechanism that can produce nested patterns of infracommunity structure (e.g. Rohde et al. 1998; Poulin and Valtonen, 2001). However, the addition of size-dependent parasites (i.e. with prevalence increasing with size due to higher feeding rates of the host and/or accumulation of parasites) to a baseline community of sizeindependent parasite species can also result in a nested structure in the absence of a strict diet shift (Zelmer and Arai, 2004). Therefore, other approaches must be combined to nested subsets analyses to determine exactly how the acquisition of parasites in relation to host age serves to structure parasite communities.

Here, we address these questions using a model species. The bogue, Boops boops (L.), is an omnivorous (trophic level 2.5-2.97), demersal to semipelagic non-migratory species of fish. It is gregarious, found on the shelf of the coastal pelagic zone at a depth range $0-350 \mathrm{~m}$ (Froese and Pauly, 2007). Although the bogue is perhaps one of the most abundant species in both the Mediterranean and the North-East Atlantic (Valle et al. 2003; Boyra et al. 2004), data on its feeding habits are scarce and somewhat ambiguous. Thus, Bell and HarmelinVivien (1983), who considered B. boops to be microphagic carnivores, found that juveniles normally feed high in the water column but, on occasions, descend 
to browse on algae within the seagrass canopy. They recorded fairly large quantities of algae eaten by juveniles, whereas Bauchot and Hureau (1986) considered that juveniles are mostly carnivorous and adults mostly herbivorous. Linde et al. (2004) classified $B$. boops as suction-feeding secondary planktivores, Karpouzi and Stergiou (2003) as omnivores, and Stergiou and Karpouzi (2002) as omnivorous with a preference for plant material but also feeding on a wide range of invertebrates. Finally, Fernández et al. (2001) suggested that B. boops is mainly herbivorous whereas Ruitton et al. (2005) have shown that grazing of algae by bogue only occurs in the post-spawning period.

$B$. boops hosts a large number of metazoan parasites (67 species) among which we identified a group of 9 species with a wide geographical distribution, forming the core of the bogue parasite fauna and consistently present in both Mediterranean and N.E. Atlantic fish (Pérez-del Olmo et al. 2007 a). A pilot study on bogue revealed positive or negative (depending on the parasite species) correlations of abundance with fish size (unpublished observations). This size-associated variability in some bogue parasites (see also Renaud et al. 1980; Saad-Fares and Combes, 1992) raises the question as to whether the observed community parameters are inherent to parasite communities in $B$. boops or merely artefacts of sampling heterogeneity with respect to fish size. Knowledge of size-related variation in parasite community composition and abundance among hosts in a fish population is essential for the adequate application of multivariate statistical analyses of entire parasite communities as biological tags of fish populations (Williams and MacKenzie, 2003, and references therein). Therefore, a study on the demography of parasite community structure as a function of size of individual hosts in bogue has important implications for investigations seeking to establish the harvest localities of fish or surveying post-oil spill recovery using bogue parasites (e.g. Power et al. 2005 ; Pérez-del Olmo et al. 2007 b).

Here, using a single population sample from a single habitat, we examine the patterns of composition and structure of parasite communities in $B$. boops along a gradient of fish sizes in order to test the prediction that species forming the core of the parasite fauna and being responsible for recognizable community structure should appear in the fish population earlier than rare and stochastic species (e.g. Vidal-Martinez et al. 1998). We provide novel data on the sequential development of an unusual sparid-metazoan system characterized by high transmission rates and low levels of host specificity, focusing on (i) variation in community parameters, (ii) distributions of 'key' parasite species, and (iii) predictability of community composition with size. We further explore data on the life-cycles, distribution and host range of the parasites in the
Mediterranean, and on host biology, to explain the observed patterns of parasite community structure.

\section{MATERIALS AND METHODS}

A total of 130 B. boops was collected by local fishermen in 2 days in June 2005 off Santa Pola (Spanish Mediterranean coast). Fish, transferred on ice to the laboratory, were measured [total length (TL, cm), standard length (SL, cm), weight (W, g)], labelled, and packed individually before being frozen. A subsample of fresh fish was examined to obtain live parasite material for a precise identification. Ecto- and endo-parasites were recovered according to a standardized protocol. All metazoan parasites were identified and counted. Worms were fixed and stored in $70 \%$ ethanol. Trematodes, monogeneans and acanthocephalans were stained with iron acetocarmine and examined as permanent mounts in Canada balsam. Nematode larvae were identified on temporary mounts in saline solution or glycerine. Voucher specimens have been deposited in the Parasite Collection of Cavanilles, Institute of Biodiversity and Evolutionary Biology, University of Valencia, Spain.

Ecological terms follow Bush et al. (1997). Species with a prevalence of $>30 \%$ will be referred to henceforth as common, those with a prevalence of $\leqslant 30 \%$ as rare and those with prevalence $<10 \%$ as accidental. Component population size refers to the total number of individuals of a given species in the total sample. Observed species density distributions within total communities in each size-class were tested for fit to the null model of no interspecific interaction (Janovy et al. 1995). Due to the nonnormal distribution of the data, Spearman rank correlations $\left(\mathrm{r}_{\mathrm{s}}\right)$ and non-parametric tests (MannWhitney $(\mathrm{M}-\mathrm{W})$ and Kruskall-Wallis $(\mathrm{K}-\mathrm{W}))$ were applied for statistical comparisons with a Bonferroni correction in post-hoc tests. Prevalences were compared with Fisher's exact test. Analyses were carried out using the statistics program SPSS ${ }^{\circledR}$ 12.0.

The data set $(\mathrm{SL} 10 \cdot 2-25 \cdot 0 \mathrm{~cm})$ was stratified into 5 size-classes with $3 \cdot 0 \mathrm{~cm}$ intervals (ranges and means in Table 2). All parasite taxa were divided into 2 groups (labelled ' $\mathrm{D}$ ' and ' $\mathrm{F}$ ' in Table 1 ; parasite assemblages referred to as DA and FA in the text) with respect to the mode of infection: (i) D, transmitted to fish directly or via cercarial penetration; and (ii) F, food-transmitted parasites. Parasites were classified into 3 categories with regard to their host specificity: (i) bogue specialists (BS); (ii) sparid generalists (SG); and (iii) generalists $(\mathrm{G})$. Parasite life-cycle and host specificity data were compiled from an exhaustive search of literature sources and both the Host-Parasite Database (http://www. nhm.ac.uk/research-curation/projects/host-parasites/ database/) and the Host-Parasite Catalogue compiled by the Natural History Museum, London. Data for 
the regional distribution of parasites were taken from a complete checklist of parasites of $B$. boops (see Pérez-del Olmo et al. 2007 a).

Nested subset analyses were carried out for the total parasite communities and separately for the separate matrices containing either directly transmitted or food-transmitted parasites using the Nestedness Temperature Calculator Program of Atmar and Patterson (1995). The latter matrices were further stratified by size-class and subjected to analysis. Matrices were packed maximally and the nestedness metric 'temperature' ( $\mathrm{T}$ ) was calculated. For each matrix, the value of $\mathrm{T}$ was compared with those of 1000 random matrices generated by Monte-Carlo simulations, with no row or column constraints, to assess the probability of randomly obtaining a matrix with the same or higher degree of order.

RESULTS

\section{Parasites of B. boops off Santa Pola}

Species composition, prevalence and abundance of each parasite in each size-class sample are summarized in Table 1. A total of 26 parasite species was found in the 130 fish examined from Santa Pola. These include 3 additional new host records (Camallanus sp., Cucullanellus sp. and Tormopsolus sp.). With respect to the mode of infection, 16 species were parasites with complex life-cycles transmitted to the final host by ingestion of the second intermediate/paratenic host. This group accounted for $84.6 \%$ of all parasites in the overall sample (range for size-class samples: 77.4-93.8\%) and included 9 species of trematode with a high representation of the superfamily Hemiuroidea (6 species, 53.5\% of individuals transmitted via food ingestion), 6 nematodes and a larval cestode. The remaining 10 species were parasites transmitted to fish directly ( 3 monogenean and 3 crustacean species) or via cercarial penetration (4 larval trematodes).

Generalist parasites comprised a considerable part of the component community in $B$. boops (16 species, $53.5 \%$ of all individuals) compared with bogue specialists ( 3 species, $35 \cdot 4 \%$ ) and sparid generalists ( 4 species, $11 \cdot 1 \%$ ). This excludes 3 taxa not identified to the species level but only being represented by 1 specimen each in the total sample (see Table 1).

Fig. 1 shows the distribution of parasites in relation to their first appearance and prevalence in the size-class samples. Thirteen species colonized the fish of size-class 1 . Seven species appeared for the first time in the second size-class and 3,2 and 1 species were added to the species lists of the subsequent samples, respectively.

Five groups of species can be distinguished with respect to their prevalence and persistence in the 5 samples stratified by size. Six species (B. israelensis,
A. stossichii, H. communis, Hysterothylacium aduncum, Microcotyle erythrini and Lecithocladium excisum) were found in all 5 samples with high prevalence $(>30 \%$, common species; except for L. excisum with a prevalence of $15 \cdot 0 \%$ in size-class 1$)$. Of these, the first 3 species were the most frequent in all 5 size-class samples (prevalence: $>60 \%$, overall range : $83-100 \%$ ) and represented the vast majority (78-95\%) of the parasites found. Three species (Cardiocephaloides longicollis, Prosorhynchus crucibulum and Scolex pleuronectis) were recovered in all samples but at low prevalences $(<30 \%$, rare species). Four species occurred at low prevalences in 4 samples, and 6 species were found with low prevalences in 2 or 3 samples. Finally, a group of 7 species occurred in only one size-class and, with the exception of Peniculus fistula, in a single fish (accidental species). There was a highly significant negative correlation between the order of the 'arrival' of the species (coded 1-5, according to the size-class) and the prevalence at which they infected fish $\left(\mathrm{r}_{\mathrm{s}}=-0 \cdot 643, P=0 \cdot 0004 ; n=26\right)$.

\section{Host size and parasite community descriptors}

All specimens of $B$. boops examined were infected with 2-13 parasite taxa and harboured 7-245 individual parasites. Species density distributions in all 5 samples were found to fit the null model of no interspecific interaction based on frequency of cooccurrences (Janovy et al. 1995). Data on the mean parasite infracommunity richness and abundance in each size-class are given in Table 2. Assemblages formed by the two parasite groups with different transmission strategies (direct $v s$ food transmitted) are presented as separate subsets.

Infracommunities tended to increase in richness and abundance with host size $\left(\mathrm{r}_{\mathrm{s}}=0 \cdot 399, P<0 \cdot 0001\right.$ and $\mathrm{r}_{\mathrm{s}}=0 \cdot 251, P=0 \cdot 004$, respectively). This positive association was stronger in DA $\left(r_{s}=0 \cdot 389\right.$, $P<0.0001$ and $r_{\mathrm{s}}=0.593, P<0.0001$, respectively) and significant for the number of species only in FA $\left(r_{s}=0 \cdot 210, P=0 \cdot 017\right)$. Furthermore, there were significant differences in the distributions of species and individual parasites among the 5 size-classes (see Table 2). These differences were largely due to the higher parasite load in the largest size-classes (4 and 5) compared to size-classes 1 and 2. With respect to the distributions of individual parasites the lowest abundance of food-transmitted parasites in size-class 2 and the substantially higher load of directly-transmitted parasites in large fish (class 4-5) contributed to the overall significant differences for total communities by size (see Table 2).

Despite the narrow range of lengths within size classes, some within-class variability was observed. Thus, there were correlations between richness or abundance and host length in some size classes (see Table 2 for details). 
Table 1. Prevalence $(\mathrm{P} \%)$ and abundance (mean, MA \pm s.D. (median shown if $>0$ only)) of parasites in the sample of Boops boops stratified by size

(na, not applicable; BS, bogue specialist; SG, sparid generalist; G, generalist; D, transmitted via direct infection; F, transmitted via food ingestion. Hemiuroideans marked with a star.)

\begin{tabular}{|c|c|c|c|c|c|c|c|c|c|c|c|}
\hline \multirow[b]{2}{*}{ Parasite species } & \multirow{2}{*}{$\begin{array}{l}\text { Mode of } \\
\text { infection \& } \\
\text { Specificity }\end{array}$} & \multicolumn{2}{|c|}{ Size-class 1} & \multicolumn{2}{|c|}{ Size-class 2} & \multicolumn{2}{|c|}{ Size-class 3} & \multicolumn{2}{|c|}{ Size-class 4} & \multicolumn{2}{|c|}{ Size-class 5} \\
\hline & & $\mathrm{P} \%$ & $\mathrm{MA} \pm$ s.D. $(\mathrm{M})$ & $\mathrm{P} \%$ & $\mathrm{MA} \pm$ s.D. (M) & $\mathrm{P} \%$ & $\mathrm{MA} \pm$ s.D. (M) & $\mathrm{P} \%$ & $M A \pm$ s.D. $(\mathrm{M})$ & $\mathrm{P} \%$ & $\mathrm{MA} \pm$ S.D. $(\mathrm{M})$ \\
\hline \multicolumn{12}{|l|}{ Monogenea } \\
\hline Cyclocotyla bellones & $\mathrm{D}, \mathrm{G}$ & - & - & - & - & $2 \cdot 9$ & $0.03 \pm 0.2$ & $17 \cdot 2$ & $0 \cdot 17 \pm 0 \cdot 4$ & $4 \cdot 8$ & $0 \cdot 05 \pm 0 \cdot 2$ \\
\hline Microcotyle erythrini & $\mathrm{D}, \mathrm{SG}$ & $35 \cdot 0$ & $1 \cdot 55 \pm 3 \cdot 2$ & $57 \cdot 7$ & $1 \cdot 31 \pm 1 \cdot 5(1)$ & $73 \cdot 5$ & $2 \cdot 12 \pm 2 \cdot 1(1)$ & $100 \cdot 0$ & $8 \cdot 83 \pm 7 \cdot 7(7)$ & $95 \cdot 2$ & $10 \cdot 19 \pm 8 \cdot 0(10)$ \\
\hline Pseudaxine trachuri & $\mathrm{D}, \mathrm{G}$ & $15 \cdot 0$ & $0 \cdot 25 \pm 0 \cdot 7$ & $7 \cdot 7$ & $0 \cdot 15 \pm 0 \cdot 6$ & $11 \cdot 8$ & $0 \cdot 21 \pm 0 \cdot 6$ & $20 \cdot 7$ & $0 \cdot 28 \pm 0 \cdot 6$ & - & - \\
\hline \multicolumn{12}{|l|}{ Digenea } \\
\hline Aphanurus stossichii ${ }^{*}$ & $\mathrm{~F}, \mathrm{G}$ & $85 \cdot 0$ & $3 \cdot 05 \pm 2 \cdot 1(3)$ & $96 \cdot 2$ & $7 \cdot 69 \pm 11 \cdot 8(4 \cdot 5)$ & $91 \cdot 2$ & $6 \cdot 38 \pm 5 \cdot 6(5)$ & $96 \cdot 6$ & $9 \cdot 28 \pm 15 \cdot 1(5)$ & $90 \cdot 5$ & $6 \cdot 29 \pm 7 \cdot 7(4)$ \\
\hline Arnola microcirrus* & $\mathrm{F}, \mathrm{SG}$ & $5 \cdot 0$ & $0 \cdot 10 \pm 0 \cdot 5$ & - & - & - & - & - & - & - & - \\
\hline Bacciger israelensis & $\mathrm{F}, \mathrm{BS}$ & $95 \cdot 0$ & $15 \cdot 25 \pm 18 \cdot 1(9)$ & $88 \cdot 5$ & $6 \cdot 58 \pm 9 \cdot 2(4 \cdot 5)$ & $94 \cdot 1$ & $10 \cdot 29 \pm 9 \cdot 0(9)$ & $82 \cdot 8$ & $16 \cdot 21 \pm 19 \cdot 6(10 \cdot 5)$ & $85 \cdot 7$ & $36 \cdot 19 \pm 53 \cdot 9(12)$ \\
\hline Cardiocephaloides longicollis met. & $\mathrm{D}, \mathrm{G}$ & $10 \cdot 0$ & $0 \cdot 20 \pm 0 \cdot 7$ & $19 \cdot 2$ & $0 \cdot 31 \pm 0 \cdot 7$ & $17 \cdot 7$ & $0 \cdot 18 \pm 0 \cdot 4$ & $20 \cdot 7$ & $0 \cdot 28 \pm 0 \cdot 6$ & $28 \cdot 57$ & $0 \cdot 43 \pm 0 \cdot 8$ \\
\hline Hemiurus communis* & $\mathrm{F}, \mathrm{G}$ & $100 \cdot 0$ & $21 \cdot 00 \pm 17 \cdot 4(18)$ & $96 \cdot 2$ & $9 \cdot 12 \pm 7 \cdot 2(6)$ & $94 \cdot 1$ & $13 \cdot 79 \pm 22 \cdot 4(8 \cdot 5)$ & $93 \cdot 1$ & $13 \cdot 93 \pm 27 \cdot 3(5)$ & $95 \cdot 2$ & $6 \cdot 76 \pm 5 \cdot 9(1)$ \\
\hline Lecithocladium excisum* & $\mathrm{F}, \mathrm{G}$ & $15 \cdot 0$ & $0 \cdot 20 \pm 0 \cdot 5$ & $34 \cdot 6$ & $0 \cdot 42 \pm 0 \cdot 6$ & $41 \cdot 2$ & $0 \cdot 65 \pm 1 \cdot 0$ & $55 \cdot 2$ & $1 \cdot 21 \pm 1 \cdot 8(1)$ & $33 \cdot 3$ & $0 \cdot 43 \pm 0 \cdot 7$ \\
\hline Magnibursatus bartolii ${ }^{*}$ & $\mathrm{~F}, \mathrm{BS}$ & - & - & - & - & - & - & $3 \cdot 4$ & $0 \cdot 03 \pm 0 \cdot 2$ & $4 \cdot 8$ & $0 \cdot 05 \pm 0 \cdot 2$ \\
\hline Opecoelidae gen. sp. & $\mathrm{F}$, na & - & - & - & - & $2 \cdot 9$ & $0 \cdot 03 \pm 0 \cdot 2$ & - & - & - & - \\
\hline Prosorhynchus crucibulum met. & $\mathrm{D}, \mathrm{G}$ & $10 \cdot 0$ & $0 \cdot 20 \pm 0 \cdot 7$ & $3 \cdot 9$ & $0 \cdot 15 \pm 0 \cdot 8$ & $20 \cdot 6$ & $2 \cdot 29 \pm 7 \cdot 4$ & $13 \cdot 8$ & $2 \cdot 34 \pm 9 \cdot 67$ & $9 \cdot 5$ & $0 \cdot 14 \pm 0 \cdot 5$ \\
\hline Robphildollfusium martinezgomezi & $\mathrm{F}, \mathrm{BS}$ & - & - & $11 \cdot 5$ & $0 \cdot 27 \pm 1 \cdot 0$ & - & - & - & - & $4 \cdot 8$ & $0 \cdot 05 \pm 0 \cdot 2$ \\
\hline Stephanostomum euzeti met. & $\mathrm{D}, \mathrm{G}$ & - & - & $11 \cdot 5$ & $0 \cdot 31 \pm 0 \cdot 9$ & $23 \cdot 5$ & $0 \cdot 29 \pm 0 \cdot 6$ & $24 \cdot 1$ & $0 \cdot 28 \pm 0 \cdot 5$ & $4 \cdot 8$ & $0 \cdot 05 \pm 0 \cdot 2$ \\
\hline Tetrochetus corypahenae* & $\mathrm{F}, \mathrm{G}$ & - & - & $3 \cdot 9$ & $0 \cdot 04 \pm 0 \cdot 2$ & - & - & - & - & - & - \\
\hline Tormopsolus sp. met. & $\mathrm{D}, \mathrm{G}$ & $5 \cdot 0$ & $0 \cdot 05 \pm 0 \cdot 2$ & - & - & $5 \cdot 9$ & $0 \cdot 06 \pm 0 \cdot 2$ & $3 \cdot 4$ & $0 \cdot 03 \pm 0 \cdot 2$ & - & - \\
\hline \multicolumn{11}{|l|}{ Cestoda } & $1 \cdot 67 \pm 6 \cdot 8$ \\
\hline \multicolumn{12}{|l|}{ Nematoda } \\
\hline Camallanus sp. & $\mathrm{F}, \mathrm{na}$ & - & - & - & - & - & $0.00 \pm 0.2$ & $\begin{array}{l}24 \cdot 1 \\
3 \cdot 4\end{array}$ & $\begin{array}{l}0 \cdot 24 \pm 0 \cdot 4 \\
0 \cdot 03 \pm 0 \cdot 2\end{array}$ & $-14 \cdot 3$ & - \\
\hline Pseudocapillaria adriatica & $\mathrm{F}, \mathrm{G}$ & - & - & $3 \cdot 9$ & $0 \cdot 04 \pm 0 \cdot 2$ & - & - & - & --- & $4 \cdot 8$ & $0 \cdot 05 \pm 0 \cdot 2$ \\
\hline Contracaecum sp. larva & $\mathrm{F}, \mathrm{G}$ & - & - & - & - & $2 \cdot 9$ & $0 \cdot 06 \pm 0 \cdot 3$ & - & - & - & - \\
\hline Cucullanellus sp. & $\mathrm{F}$, na & - & - & $3 \cdot 9$ & $0 \cdot 04 \pm 0 \cdot 2$ & - & - & - & - & - & - \\
\hline Hysterothylacium aduncum larva & $\mathrm{F}, \mathrm{G}$ & $35 \cdot 0$ & $0 \cdot 50 \pm 0 \cdot 8$ & $61 \cdot 5$ & $0 \cdot 96 \pm 1 \cdot 1$ & $44 \cdot 1$ & $0 \cdot 79 \pm 1 \cdot 0$ & $69 \cdot 0$ & $1 \cdot 17 \pm 1 \cdot 2(1)$ & $81 \cdot 0$ & $1 \cdot 86 \pm 1 \cdot 6$ \\
\hline \multicolumn{12}{|l|}{ Isopoda } \\
\hline Ceratothoa oestroides & $\mathrm{D}, \mathrm{SG}$ & $5 \cdot 0$ & $0 \cdot 40 \pm 1 \cdot 8$ & - & - & $2 \cdot 9$ & $0 \cdot 03 \pm 0 \cdot 2$ & - & - & $4 \cdot 8$ & $0 \cdot 05 \pm 0 \cdot 2$ \\
\hline \multicolumn{12}{|l|}{ Copepoda } \\
\hline Naobranchia cygniformis & $\mathrm{D}, \mathrm{SG}$ & - & - & $19 \cdot 2$ & $0 \cdot 19 \pm 0 \cdot 4$ & $20 \cdot 6$ & $0 \cdot 21 \pm 0 \cdot 4$ & $24 \cdot 1$ & $0 \cdot 31 \pm 0 \cdot 6$ & $19 \cdot 1$ & $0 \cdot 19 \pm 0 \cdot 4$ \\
\hline Peniculus fistula & $\mathrm{D}, \mathrm{G}$ & - & - & - & - & - & - & - & - & $9 \cdot 5$ & $0 \cdot 10 \pm 0 \cdot 3$ \\
\hline Component community richness & & & 13 & & 17 & & 18 & & 17 & & 18 \\
\hline $\begin{array}{l}\text { Proportion of individuals } \\
\text { transmitted via food chain }\end{array}$ & & & $0 \cdot 94$ & & $0 \cdot 91$ & & $0 \cdot 86$ & & $0 \cdot 77$ & & $0 \cdot 83$ \\
\hline Proportion of generalist individuals & & & $0 \cdot 60$ & & $0 \cdot 70$ & & $0 \cdot 66$ & & $0 \cdot 54$ & & $0 \cdot 28$ \\
\hline
\end{tabular}


Class 1 Class 2 Class 3 Class 4 Class 5

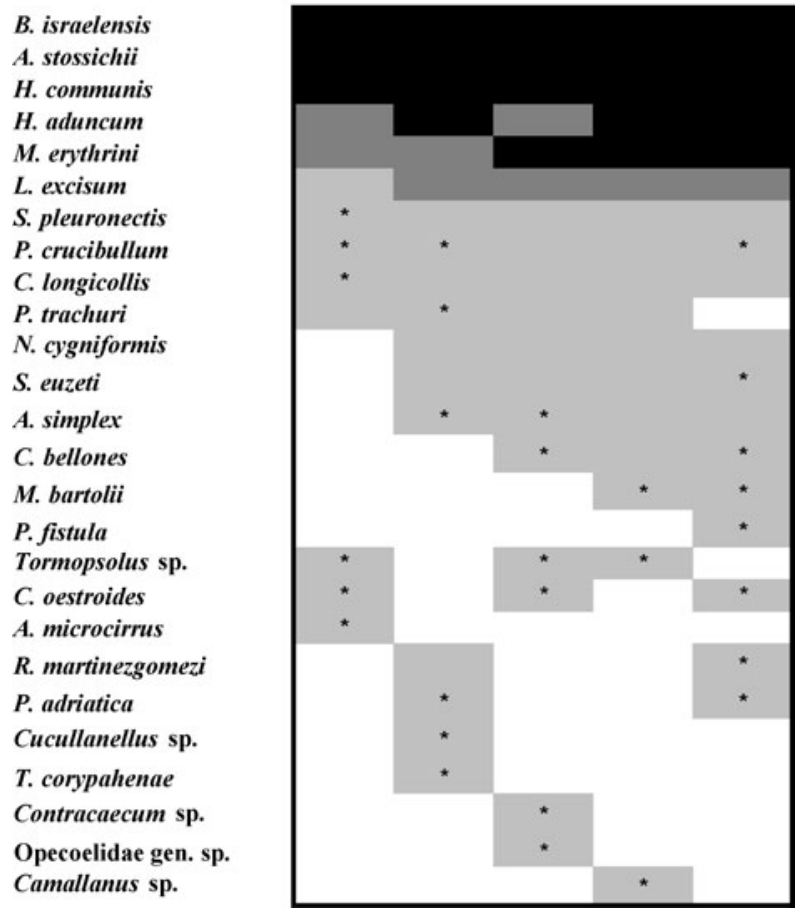

Fig. 1. Schematic illustration of colonization and persistence (order of appearance and prevalence status) of bogue parasites in the component communities of the five size-class samples. $\square$, prevalence $>60 \%$; $\square$, prevalence $30-60 \%$; $\square$, prevalence $10-30 \%$; $₫$, prevalence $<10 \%$.

\section{Key parasite species}

Six species (1 bogue specialist, 1 sparid generalist and 4 generalists) were present in all size samples (most with prevalences of $>60 \%$ in at least 3 samples, see Fig. 1), and represented the majority of the parasites recovered in each size-class $(96 \cdot 8,93.9$, $90 \cdot 3,91 \cdot 5$ and $95 \cdot 2 \%$ of all individuals, respectively). Of these, B. israelensis, H. aduncum and M. erythrini showed a positive correlation between abundance and fish size $\left(\mathrm{r}_{\mathrm{s}}=0.179, P=0.041 ; \mathrm{r}_{\mathrm{s}}=0.281, P=\right.$ 0.001 ; and $r_{\mathrm{s}}=0.646 ; P<0.0001$, respectively) in contrast to $H$. communis that exhibited a negative association $\left(\mathrm{r}_{\mathrm{s}}=-0.379 ; P<0 \cdot 0001\right)$. No significant relationship was found for $A$. stossichii and $L$. excisum.

A tendency for an increase in prevalence with size was detected for $H$. aduncum $\left(\chi^{2}=8 \cdot 284 ; P=0 \cdot 004\right)$ and $M$. erythrini $\left(\chi^{2}=30.954 ; P<0.0001\right)$. However, with the exception of the monogenean $M$. erythrini, which had distinctly higher prevalences in the largest fish (classes 4-5 as compared to 1-2), the prevalence of infection by the dominant species did not differ significantly among the 5 size-classes of fish (see Fig. 2A). The abundance of $M$. erythrini also exhibited the most significant differences between sizeclasses (all $P<0 \cdot 00001$ ), following the prevalence divergence pattern (Fig. 2B). The abundance of the other key species exhibited a few significant differences among size samples (Fig. 2B). A comparison of the within-class abundance distributions of the 3 most abundant trematode species showed significant differences exclusively in size-class 1 and 5. The smallest fish had more individuals of $H$. communis than $A$. stossichii and B. israelensis $(P<0.0001 ; P=0.023)$, whereas in the largest fish, there were more individuals of $B$. israelensis $(P=0 \cdot 014 ; P=0 \cdot 006)$.

There was a strong positive correlation $\left(r_{\mathrm{s}}=\right.$ $0 \cdot 813, P=0.008)$ between the regional distribution (measured by the number of records in Pérez delOlmo et al. 2007a) and local prevalence in our total sample of 9 taxa (B. israelensis, A. stossichii, H. communis, L. excisum, H. aduncum, Anisakis simplex, M. erythrini and Ceratothoa oestroides, forming the core of bogue fauna, plus unidentified tetraphyllidean larva Scolex pleuronectis) known from both the Mediterranean and Atlantic.

\section{Host size and non-random community structure}

The pooled infracommunities in B. boops produced a significantly nested matrix, as did the assemblages, resulting from food ingestion (FA) and direct infection (DA) (Table 3). There were significant correlations between the standard length of individual fish and their rank order in the packed matrix in the total community and FA datasets (the latter being rather weak, with low values for both $r_{\mathrm{s}}$ and $P$ ) but not in the DA dataset. Significant nested subset patterns were observed among FA of the 5 size-classes, as well as among DA of the larger fish (size-classes 3-5). With the exception of class $4 \mathrm{DA}$, no significant association between the rank order and size of fish was detected (Table 3).

In contrast, there was a strong association between the rank position in the matrix and component population size of parasites (total communities, $\mathrm{r}_{\mathrm{s}}=$ $-0.961, P<0.0001 ; \mathrm{FA}, \mathrm{r}_{\mathrm{s}}=-0.949, P<0.0001$; DA, $\left.\mathrm{r}_{\mathrm{s}}=-0.854, P=0.0016\right)$. Furthermore, the order of species in the packed matrix of total communities was not related to either the mode of transmission (direct infection vs via food ingestion, $P>0 \cdot 05$ ) or host specificity (generalists $v s$ specialists, $P>0 \cdot 05)$. The 6 'key' species exhibited consistently the highest ranks in all subsets.

With the exception of $M$. erythrini, these key species also exhibited the most idiosyncratic distributions, which resulted in a characteristic gradual increase to a peak, of idiosyncratic temperatures of the infracommunities with the lowest richness in DA subsets (pooled and size-class 2-5 sets). Generally, the 'kinds' of species contributing to 'erosion' of the uniform distributions of temperatures across hosts differed between FA and DA. Three main groups were distinguished: (i) species 'unexpectedly' present in most species-poor assemblages, (ii) species with erratic occurrence showing both 
Table 2. Community parameters of parasite assemblages, significance of differences and length correlations of infracommunity richness and abundance in the 5 size subsamples of Boops boops

(Abbreviations as in the Material and Methods section; ns, $P>0 \cdot 05$.)

\begin{tabular}{|c|c|c|c|c|c|c|}
\hline & $\begin{array}{l}\text { Size-class } 1 \\
(n=20)\end{array}$ & $\begin{array}{l}\text { Size-class } 2 \\
(n=26)\end{array}$ & $\begin{array}{l}\text { Size-class } 3 \\
(n=34)\end{array}$ & $\begin{array}{l}\text { Size-class } 4 \\
(n=29)\end{array}$ & $\begin{array}{l}\text { Size-class } 5 \\
(n=21)\end{array}$ & $\begin{array}{l}\text { Significance } \\
\text { of differences }\end{array}$ \\
\hline Fish total length [TL, range (mean) in $\mathrm{cm}]$ & $12 \cdot 8-15 \cdot 1(13 \cdot 9)$ & $15 \cdot 5-18 \cdot 5(17 \cdot 0)$ & $18 \cdot 3-22 \cdot 0(20 \cdot 4)$ & $21 \cdot 7-27 \cdot 0(23 \cdot 6)$ & $25 \cdot 5-29 \cdot 6(26 \cdot 9)$ & - \\
\hline Fish standard length $[\mathrm{SL}$, range (mean) in $\mathrm{cm}]$ & $10 \cdot 2-12 \cdot 9(11 \cdot 9)$ & $13 \cdot 2-15 \cdot 7(14 \cdot 7)$ & $16 \cdot 0-18 \cdot 9(17 \cdot 4)$ & $19 \cdot 0-21 \cdot 9(20 \cdot 5)$ & $22 \cdot 0-25 \cdot 0(23 \cdot 2)$ & - \\
\hline \multicolumn{7}{|l|}{ Total communities } \\
\hline Mean no. of species \pm S.D. & $4 \cdot 25 \pm 1 \cdot 2$ & $5 \cdot 38 \pm 1 \cdot 5$ & $5 \cdot 74 \pm 1 \cdot 6$ & $6 \cdot 72 \pm 1 \cdot 9$ & $6 \cdot 10 \pm 1 \cdot 5$ & $\begin{array}{c}\mathrm{K}-\mathrm{W} \mathrm{H}=27 \cdot 11 \\
P<0 \cdot 00001\end{array}$ \\
\hline Mean no. of individuals \pm s.D. & $42 \cdot 90 \pm 22 \cdot 1$ & $27 \cdot 77 \pm 15 \cdot 1$ & $37 \cdot 68 \pm 25 \cdot 8$ & $55 \cdot 34 \pm 44 \cdot 5$ & $64 \cdot 86 \pm 52 \cdot 2$ & $\begin{array}{c}\mathrm{K}-\mathrm{W} \mathrm{H}=20 \cdot 50 \\
P=0 \cdot 0004\end{array}$ \\
\hline No. of species $v s$ Fish length $\left(\mathrm{r}_{\mathrm{s}}, \mathrm{P}\right)$ & ns & $\begin{array}{l}\mathrm{r}_{\mathrm{s}}=0 \cdot 398 \\
P=0 \cdot 044\end{array}$ & ns & $\begin{array}{c}\mathrm{r}_{\mathrm{s}}=-0 \cdot 443 \\
P=0 \cdot 016\end{array}$ & ns & - \\
\hline No. of individuals $v s$ Fish length $\left(\mathrm{r}_{\mathrm{s}}, \mathrm{P}\right)$ & ns & ns & ns & $\begin{array}{c}\mathrm{r}_{\mathrm{s}}=-0 \cdot 380 \\
P=0.042\end{array}$ & $\begin{array}{l}\mathrm{r}_{\mathrm{s}}=0 \cdot 511 \\
P=0 \cdot 018\end{array}$ & - \\
\hline \multicolumn{7}{|l|}{ Assemblages resulting from food ingestion (FA) } \\
\hline Total no. of species & 7 & 11 & 9 & 9 & 10 & - \\
\hline Mean no. of species \pm s.D. & $3 \cdot 45 \pm 0 \cdot 8$ & $4 \cdot 19 \pm 1 \cdot 0$ & $3 \cdot 94 \pm 1 \cdot 0$ & $4 \cdot 48 \pm 1 \cdot 3$ & $4 \cdot 33 \pm 1 \cdot 1$ & $\begin{array}{c}\mathrm{K}-\mathrm{W} \mathrm{H}=11 \cdot 24 \\
P=0 \cdot 0239\end{array}$ \\
\hline Mean no. of individuals \pm s.D. & $40 \cdot 25 \pm 21 \cdot 6$ & $25 \cdot 35 \pm 14 \cdot 7$ & $32 \cdot 26 \pm 25 \cdot 5$ & $42 \cdot 83 \pm 42 \cdot 2$ & $53 \cdot 67 \pm 51 \cdot 9$ & $\begin{array}{c}\mathrm{K}-\mathrm{W} \mathrm{H}=11 \cdot 75 \\
P=0 \cdot 0193\end{array}$ \\
\hline No. of species $v s$ Fish length $\left(\mathrm{r}_{\mathrm{s}}, \mathrm{P}\right)$ & ns & $\begin{array}{l}\mathrm{r}_{\mathrm{s}}=0 \cdot 405 \\
P=0 \cdot 040\end{array}$ & ns & ns & ns & - \\
\hline No. of individuals $v s$ Fish length $\left(\mathrm{r}_{\mathrm{s}}, \mathrm{P}\right)$ & ns & ns & ns & ns & $\begin{array}{l}\mathrm{r}_{\mathrm{s}}=0 \cdot 493 \\
P=0 \cdot 023\end{array}$ & - \\
\hline \multicolumn{7}{|c|}{ Assemblages resulting from direct infection (DA) } \\
\hline Total no. of species & 6 & 6 & 9 & 8 & 8 & - \\
\hline Mean no. of species \pm s.D. & $0 \cdot 80 \pm 0 \cdot 7$ & $1 \cdot 19 \pm 0 \cdot 8$ & $1 \cdot 79 \pm 1 \cdot 1$ & $2 \cdot 24 \pm 1 \cdot 18$ & $1 \cdot 76 \pm 0 \cdot 8$ & $\begin{array}{c}\mathrm{K}-\mathrm{W} \mathrm{H}=27 \cdot 15 \\
P<0 \cdot 00001\end{array}$ \\
\hline Mean no. of individuals \pm s.D. & $2 \cdot 65 \pm 3 \cdot 9$ & $2 \cdot 42 \pm 1 \cdot 9$ & $5 \cdot 41 \pm 7 \cdot 7$ & $12 \cdot 52 \pm 11 \cdot 9$ & $11 \cdot 19 \pm 7 \cdot 7$ & $\begin{array}{l}\mathrm{K}-\mathrm{W} \mathrm{H}=51 \cdot 51 \\
P<0 \cdot 00001\end{array}$ \\
\hline No. of species $v$ s Fish length $\left(\mathrm{r}_{\mathrm{s}}, \mathrm{P}\right)$ & ns & $\mathrm{ns}$ & ns & $\begin{array}{c}\mathrm{r}_{\mathrm{s}}=-0 \cdot 434 \\
P=0.019\end{array}$ & ns & - \\
\hline No. of individuals $v s$ Fish length $\left(\mathrm{r}_{\mathrm{s}}, \mathrm{P}\right)$ & ns & ns & ns & ns & ns & - \\
\hline
\end{tabular}




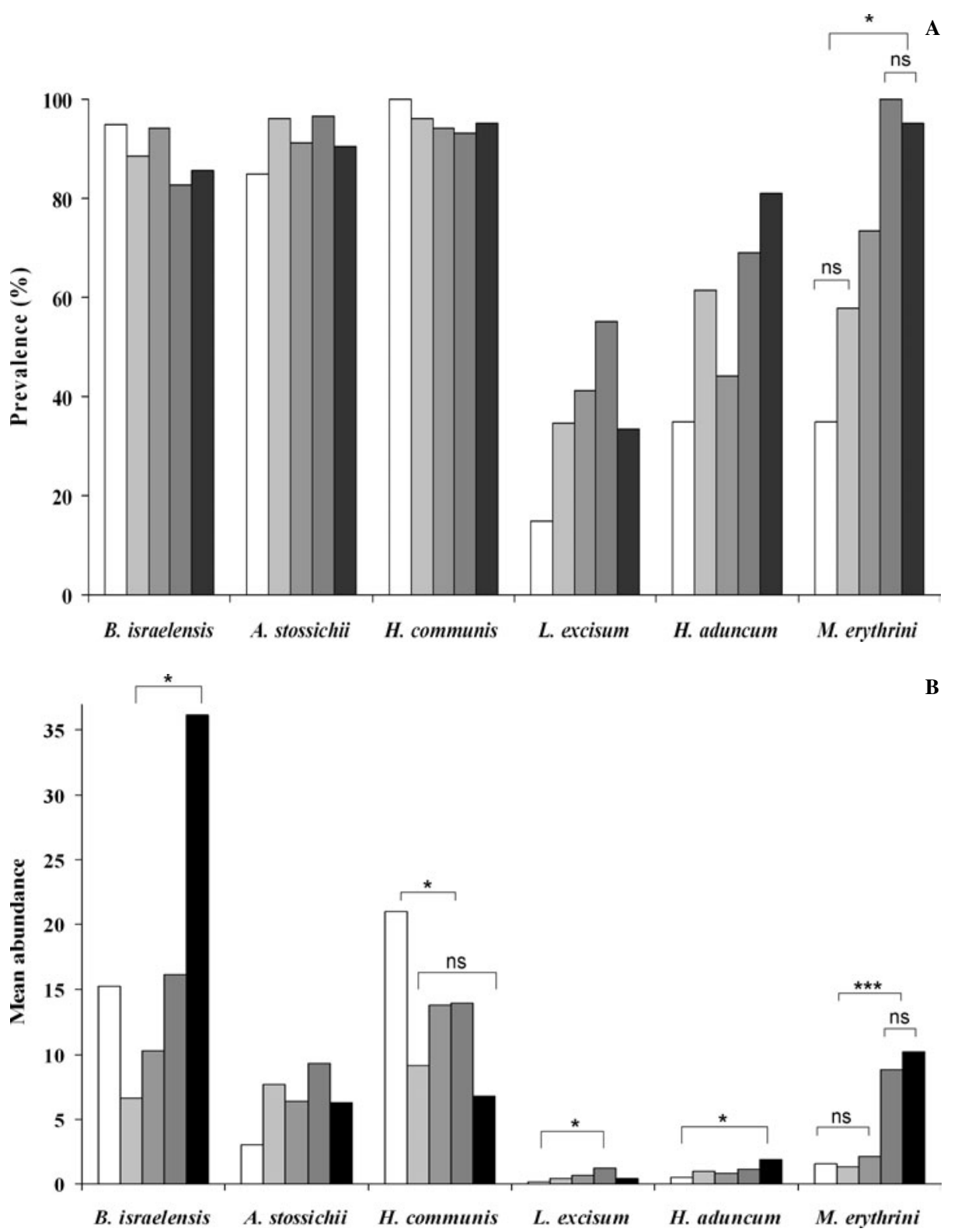

Fig. 2. Prevalence (A) and mean abundance (B) of the key species in parasite communities of Boops boops off Santa Pola. Error bars omitted for clarity. Differences between host size classes (the 5 columns, in order) indicated by asterisks (*, $P<0 \cdot 05$; ***, $P<0 \cdot 001$; ns, not significant).

unexpected absences and presences, and (iii) species with low occurrence showing a few accidental unexpected presences. The first group was only detected in FA and consisted of the 3 most prevalent species (B.israelensis, H. communis, and A. stossichii), whereas the species of the third group were mostly represented in the DA (see Table 3 ). Species of the second group were detected in both DA (P. crucibulum, C. longicollis and N. cygniformis) and FA (H. aduncum, L. excisum and S. pleuronectis).

\section{DISCUSSION}

The 26 species found in this study comprised $\sim 40 \%$ of the parasites of $B$. boops throughout its distributional range (67 species; see Pérez-del Olmo et al. $2007 a$ ). A characteristic feature of the parasite community in B. boops off Santa Pola was the high representation of parasites with complex life-cycles that are transmitted to fish via food ingestion (16 species comprising $>80 \%$ of all parasite individuals) and the dominance of trematodes (mostly hemiuroids, comprising more than half of the individuals transmitted via the food chain in the total sample). The present data only partially support the suggestion for a strong phylogenetic element of the trematode fauna of sparids (Bartoli et al. 2005), since generalist parasites transmitted to $B$. boops from other sympatric species comprised a large percentage of the community ( $62 \%$ of all species and $>50 \%$ of all individuals). Of the 3 bogue specialists, only B. israelensis exhibited substantial abundance. 
Table 3. Nested subset analyses results for the metazoan infra-assemblages in Boops boops from off Santa Pola (1000 Monte-Carlo simulation runs)

(ns, not significant; AMIC, A. microcirrus; ASTO, A. stossichii; BISR, B. israelensis; CBEL, C. bellones; CLON, C. longicollis; COES, C. oestroides; HADU, H. aduncum; HCOM, H. communis; LEXC, L. excisum; MERY, M. erythrini; NCYG, N.cygniformis; PCRU, P. crucibulum; PFIS, P. fistula; PTRA, P. trachuri; SEUZ, S. euzeti; SPLE, S. pleuronectis; TORM, Tormopsolus sp.)

\begin{tabular}{|c|c|c|c|c|c|c|c|}
\hline Data set & $\begin{array}{l}\text { Matrix } \\
\text { temperature }\end{array}$ & $\begin{array}{l}\text { Matrix } \\
\text { fill }(\%)\end{array}$ & $\begin{array}{l}\text { Random } \\
\text { temperature } \\
\pm \text { s.D. }\end{array}$ & $P$ value & $\begin{array}{l}\text { Correlation } \\
\text { between host } \\
\text { rank in packed } \\
\text { matrix and SL }\end{array}$ & Top colonisers & $\begin{array}{l}\text { Idiosyncratic species } \\
\text { (top colonisers marked with a } * \text { ) }\end{array}$ \\
\hline $\begin{array}{l}\text { Total metazoan } \\
\text { communities }\end{array}$ & $13 \cdot 7$ & $21 \cdot 9$ & $62 \cdot 3 \pm 2 \cdot 5$ & $3 \cdot 75 \cdot 10^{-62}$ & $\begin{array}{l}\mathrm{r}_{\mathrm{s}}=-0 \cdot 349 \\
P<0 \cdot 0001\end{array}$ & HCOM; ASTO; BISR; MERY; HADU & $\begin{array}{l}\text { BISR*; HADU* }{ }^{*} \text { MERY* ; ASTO** } \\
\text { LEXC; CLON; SPLE; NCYG }\end{array}$ \\
\hline $\begin{array}{l}\text { Assemblages } \\
\text { resulting from } \\
\text { food ingestion (FA) }\end{array}$ & $13 \cdot 1$ & $25 \cdot 6$ & $60 \cdot 6 \pm 3$ & $4 \cdot 59 \cdot 10^{-47}$ & $\begin{array}{l}\mathrm{r}_{\mathrm{s}}=-0 \cdot 191 \\
P=0 \cdot 03\end{array}$ & ASTO; HCOM; BISR; HADU; LEXC & BISR* ${ }^{*} \mathrm{HCOM}^{*} ; \mathrm{HADU}^{*} ; \mathrm{LEXC}^{*}$ \\
\hline Size-class 1 & $11 \cdot 8$ & $49 \cdot 2$ & $49 \cdot 2 \pm 7 \cdot 9$ & $9 \cdot 69 \cdot 10^{-7}$ & ns & HCOM; BISR; ASTO; HADU; LEXC & LEXC** BISR* ${ }^{*}$; HADU* ${ }^{*}$; AMIC \\
\hline Size-class 2 & $16 \cdot 7$ & $38 \cdot 1$ & $54 \cdot 6+6 \cdot 5$ & $2 \cdot 69 \cdot 10^{-9}$ & ns & HCOM; ASTO; BISR; HADU; LEXC & ASTO*: SPLE; BISR*: LEXC* \\
\hline Size-class 3 & $14 \cdot 8$ & $43 \cdot 7$ & $54 \cdot 8 \pm 5 \cdot 8$ & $3 \cdot 83 \cdot 10^{-12}$ & ns & BISR; HCOM; ASTO; LEXC; HADU & ASTO*; HCOM $*$; SPLE; LEXC* \\
\hline Size-class 4 & $11 \cdot 2$ & $49 \cdot 8$ & $54 \cdot 7 \pm 6 \cdot 1$ & $5 \cdot 05 \cdot 10^{-13}$ & ns & ASTO; HCOM; BISR; HADU; LEXC & BISR*; LEXC* ; HADU* ; HCOM* \\
\hline Size-class 5 & $20 \cdot 2$ & $43 \cdot 3$ & $52 \cdot 9 \pm 7 \cdot 0$ & $1 \cdot 46 \cdot 10^{-6}$ & ns & ASTO; HCOM; BISR; HADU; LEXC & BISR*; HADU* ${ }^{*}$ HCOM* $*$ LEXC* \\
\hline $\begin{array}{l}\text { Assemblages } \\
\text { resulting from } \\
\text { direct infection (DA) }\end{array}$ & $12 \cdot 1$ & $18 \cdot 4$ & $44 \cdot 6 \pm 4 \cdot 0$ & $1 \cdot 86 \cdot 10^{-16}$ & ns & MERY; CLON; NCYG; SEUZ; PTRA & PFIS; PCRU; TORM \\
\hline Size-class 1 & $59 \cdot 3$ & $20 \cdot 5$ & $29 \cdot 2 \pm 11 \cdot 9$ & ns & ns & MERY; PTRA; TORM & PCRU; CLON \\
\hline Size-class 2 & $23 \cdot 3$ & $23 \cdot 4$ & $35 \cdot 9 \pm 9 \cdot 7$ & ns & ns & MERY; CLON; NCYG & PCRU; CLON* \\
\hline Size-class 3 & $13 \cdot 7$ & $23 \cdot 3$ & $41 \cdot 0 \pm 7 \cdot 4$ & $1 \cdot 17 \cdot 10^{-4}$ & ns & MERY; SEUZ; CLON & NCYG; PCRU \\
\hline Size-class 4 & $15 \cdot 9$ & $28 \cdot 0$ & $45 \cdot 3 \pm 7 \cdot 9$ & $9 \cdot 10^{-5}$ & $\begin{array}{l}\mathrm{r}_{\mathrm{s}}=0.407 \\
P=0.03\end{array}$ & MERY; SEUZ; NCYG & PCRU; TORM; CLON \\
\hline Size-class 5 & $13 \cdot 0$ & $22 \cdot 0$ & $34 \cdot 9 \pm 8 \cdot 7$ & $0 \cdot 005$ & ns & MERY; CLON; NCYG & COES; CBEL \\
\hline
\end{tabular}


The observed sequence of infection with parasites of bogue size-classes clearly supports the hypothesis that species with wide geographical distributions should appear in the fish population earlier than rare and stochastic species since all helminths (7 species) and the isopod Ceratothoa oestroides identified as the 'core' of the bogue parasite fauna were already present in size-class 1 comprised of juvenile 1 -yearold fish. Furthermore, 6 of these key parasites in developing communities persisted as common (prevalence typically of $>60 \%$ ) in all subsequent size samples and represented the vast majority $(>90 \%)$ of the individuals. Finally, all species added to communities in larger fish were either rare or accidental; only 5 persisted in subsequent size-class samples, but showing low intensities of infection.

The present observations are supported by the data on another large Mediterranean sample of $B$. boops from the Gulf of Lion, which includes fish sizes below the range of Santa Pola sample (Renaud et al. 1980). These authors found that 6 of the 'core' bogue parasites infect fish of smaller size (juveniles as small as $11 \mathrm{~cm}$ (TL); $9 \mathrm{~cm}$ for B. israelensis) and are consistently present in larger fish (up to $20 \mathrm{~cm}$ ). These include the 4 key species of our study (i.e. B. israelensis, A. stossichii, H. communis and H. aduncum) plus the isopods Ceratothoa paralella and $C$. oestroides. Saad-Fares and Combes (1992) also found that B. israelensis and A. stossichii infect bogue off Lebanon at an early age (young-of-the-year juvenile fish; forklength: $<10 \mathrm{~cm}$ ).

In spite of the uncertainties regarding the diet of bogue, the most detailed surveys clearly demonstrate that copepods represent the prevailing portion of its food $(55 \cdot 7 \%$ and $98.0 \%$, respectively; see Jukic, 1972 for data from Eastern Mediterranean and Bell and Harmelin-Vivien, 1983 for data from Western Mediterranean). Information on parasite life-cycles supports this notion, since harpacticoids (Acartia spp.) act as intermediate hosts for 4 common species (H. communis, A. stossichii, L. excisum and H. aduncum) and indicate 3 additional alternative routes of transmission for the key parasites of bogue: (i) ctenophores (H. communis, L. excisum, B. israelensis and $H$. aduncum), (ii) chaetognaths (H. communis and A. stossichii), and (iii) amphipods (B. israelensis and $H$. aduncum). Furthermore, the presence of 7 accidental species can be also attributed to transmission via either the main food resource (e.g. harpacticoid and calanoid copepods (Contracaecum sp., A. simplex, $M$. bartolii and A. microcirrus) or chaetognaths ( $T$. coryphaenae and $A$. simplex) and plants (R. martinezgomezi)).

The only species that exhibited a notable positive correlation with size and an increase in both prevalence and abundance in the larger size-classes (SL $>19 \mathrm{~cm}$, over 4 years old) was the directly transmitted monogenean $M$. erythrini. This species appeared on the gills of the smallest fish $(\mathrm{SL}=10 \cdot 2 \mathrm{~cm})$ and persisted thereafter, but at much lower prevalence and abundance in younger fish (1-3 years old). Host body size is perhaps the main determinant of monogenean species richness and abundance due to increased gill habitat heterogeneity and surface in larger fish (Rohde, 1989); this may explain the observed increase of infection levels of $M$. erythrini in older fish.

Overall, the correlation with size of the abundance of the other key parasites (all diet-transmitted) was either not significant (A. stossichii and L. excisum), weakly positive (B. bacciger and $H$. aduncum) or moderately negative (H. communis). Whereas the association of the abundance of $H$. aduncum and size is due to a slight larval accumulation as a function of fish age (Poulin, 2000), the differences in abundance distributions of $H$. communis between juvenile (SL 10.2-12.9 cm; 1 year old) and larger fish $(\mathrm{SL}>13.0 \mathrm{~cm}, 2-8$ years old) may indicate differential microhabitat use. For most demersal fish species, there is a trend for fish size to increase with depth, with juveniles occurring in shallower waters and older fish at greater depths (Cushing, 1976; MacPherson and Duarte, 1991). Studies of fish landings from different types of fishing gear in the Mediterranean support this tendency for B. boops, since purse seine landings off Lebanon were exclusively comprised of juvenile young-of-the-year individuals (TL $5 \cdot 40-14 \cdot 30 \mathrm{~cm}$; Bariche et al. 2006) and a discard study in North West Mediterranean indicates that bogue collected by bottom trawl between 14 and $35 \mathrm{~m}$ were all small-sized juveniles (Sánchez et al. 2004). Visual fish counts in the area close to Santa Pola have shown that B. boops were represented predominantly by fish in the larger size categories (TL 20-29 cm), with no juvenile fish being recorded at depths between 35 and $40 \mathrm{~m}$ where adults were found at highest abundances. On the other hand, the juvenile fish cohort ( TL $<15 \mathrm{~cm}$ ) was much less abundant in the overall counts and only observed at somewhat lower depths $(30 \mathrm{~m})$ where no adults were recorded (Dempster et al. 2002). These data support the hypothesis of a bathymetric juvenile-mature segregation effect on the distribution of $H$. communis within the bogue population off Santa Pola.

Parasite infracommunities were rich and abundant from an early age. The observed complexity of FA, in particular, meets the prediction of Kennedy et al. (1986) for diverse helminth communities in hosts with selective feeding on prey that serve as intermediate hosts for a wide variety of helminths. Although infracommunities tended to increase in richness and abundance with host size, the differences in richness/abundance distributions were mostly due to the higher infection levels in older fish $(\mathrm{SL}>19 \mathrm{~cm}, 4-8$ years old), perhaps related to an increase in feeding rates. Since trematodes encysting on vegetation and transmitted to fish via grazing 
are few (Bartoli, 1987; Jousson and Bartoli, 1999), we expected that a notable decrease of both richness and abundance in older fish would support the statement made by Bauchot and Hureau (1986) that juveniles are predominantly carnivorous and adults mostly herbivorous. However, we did not observe an abrupt change in parameters to indicate an ontogenetic diet shift; rather, our data suggest that plant grazing by bogue is only occasional and does not affect the assemblages of food-transmitted parasites (see also Ruitton et al. 2005). The observed variability and lower abundance of infracommunities in size-class 2 might relate to increased vagility as an effect of a transition in bathymetric distribution of fish reaching maturity or to the presence of 1-year-old fish in this sample.

Although bogue parasite communities and those of gastrointestinal parasites, in particular, were rich and abundant, we found no supportive evidence for interspecific competition. The present results indicate a neutral structure in all 5 size-class subsamples, since no departures from the null model of independent acquisition were observed in the species density distributions (Janovy et al. 1995). Species co-existence in our system appears to be favoured by the different microhabitats utilized by the parasites. Indeed, the most abundant and prevalent species in our study did not exhibit substantial microhabitat overlap. M. erythrini is a gill parasite, $A$. stossichii inhabited the oesophagus and anterior stomach, whereas H. communis and L. excisum were found predominantly in the posterior stomach, and B. israelensis in the caeca.

A key result was the recognition of repeatable community structure across size/age cohorts of $B$. boops which translated into a nested subset pattern at the lowest scale, i.e. infracommunities within the individual cohorts. This was not unexpected, considering previous studies on developing communities (Poulin and Valtonen, 2001; Timi and Poulin, 2003; Vidal-Martinez and Poulin, 2003) and the high richness and abundance of infracommunities in bogue resulting from lowered specificity and the presence of several species utilizing more than a single route of transmission. However, the higherlevel order that delineates predictability of parasite community structure in Santa Pola's bogue could not be completely attributed to either accumulation over time or segregation of species among different size-class hosts. Thus, although the total communities exhibited significant moderate correlation between host rank positions in the packed matrix and size, the 2 assemblages (FA and DA) differed. FA exhibited a weak correlation with size, whereas no significant correlation was detected in DA. Furthermore, nested patterns were repeated in virtually all size-class subsets within a fairly narrow size range and in the absence of significant correlations between host rank positions and fish size.
Finally, key parasites both contributed to, and reduced nestedness, and there was a strong association between the rank position in the matrix and component population size of parasite species.

Poulin and Guégan (2000) suggested a possible link between non-random community compositional patterns and a positive relationship between spatial distribution and local abundance of faunas. The present study system seems to provide an illustration of this prediction. Thus, the strong positive correlation between the regional distribution and local abundance of the core species of bogue fauna observed at both component and infracommunity levels, and the fact that these largely contributed to the homogeneity in parasite community structure and composition in Santa Pola's bogue population, both support the prediction.

In addition to being an unusual sparid, with respect to the specificity of its parasites, bogue appears to be the best candidate (at least among the Mediterranean omnivorous fishes) to provide a setting for the action of passive sampling as a mechanism leading to non-random parasite community structure. Mouth size is one of the most important factors determining foraging ability and consequently fish diet (Breck, 1993; Magnhagen and Heibo, 2001). Karpouzi and Stergiou (2003) have shown that bogue possesses the smallest mouth dimensions among 18 Mediterranean species (including a group of 12 omnivorous species). Ontogenetic changes in diet often are related to alterations in mouth structures (Castro and Hernández-García, 1995). However, Stergiou and Karpouzi (2002) have not reported significant alterations in mouth structures of $B$. boops with increasing body size. This information, together with the exceptionally slow increase in mouth area with length (Karpouzi and Stergiou, 2003) which does not allow consumption of large prey by $B$. boops during its life span, suggests that individual fish are homogeneous and equally accessible to food-transmitted parasites. This proposal is supported by the fact that bogue attains its maximum trophic level early in its life span (at $20 \mathrm{~cm}$ (size-class 3 in our study), see Stergiou and Karpouzi, 2002). On the other hand, suction feeding does not allow for active prey selection.

The small mouth size/area in B. boops coupled with suction feeding, while restricting prey size to small invertebrates suspended in the water column, thus facilitates passive ingestion of substantial quantities of potential second intermediate hosts of the key food-transmitted parasite species (copepods, chaetognaths, ctenophores and occasionally small amphipods), which explains their co-occurrence in all size groups and few differences in abundance. However, this non-selective feeding pattern also leads to ingestion of a large additional suite of parasites utilizing the same intermediate host groups. This addition to a baseline community of key parasite species results 
in a nested structure which is linked to the differential species abundance rather than fish size.

We are grateful to Dr Jean-Paul Trilles, University of Montpellier, France, for his help in identification of Ceratothoa spp. Thanks are due to Dr Javier Aznar for advice during the study, and Tamara García for technical assistance (University of Valencia). This work was supported by project CTM2006-07106/MAR (MEC) and FEDER funds. A.P.O. benefits from a grant from MEC and a Visiting Studentship to the University of Otago, Dunedin, NZ; A.K. benefits from a Marie Curie grant FP6-MTKD-CT-2004-003175; M.F. is supported by a 'Ramón y Cajal' contract (MCY'T, Spain).

\section{REFERENCES}

Atmar, W. and Patterson, B. D. (1995). The Nestedness Temperature Calculator: a Visual Basic Program, including 294 Presence-Absence Matrices. AICS Res. Inc., University Park, New Mexico, and The Field Mus., Chicago, USA. (http://aicsresearch.com/ nestedness/tempcalc.html).

Bariche, M., Alwan, N. and El-Fadel, M. (2006). Structure and biological characteristics of purse seine landings off the Lebanese coast (eastern Mediterranean). Fisheries Research 82, 246-252.

Bartoli, P. (1987). Caractères adaptifs originaux des Digènes intestinaux de Sarpa salpa (Teleostei, Sparidae) et leur interprétation en termes d'évolution. Annales de Parasitologie Humaine et Comparée 62, 542-576.

Bartoli, P., Gibson, D. I. and Bray, R. A. (2005). Digenean species diversity in teleost fish from a nature reserve off Corsica, France (Western Mediterranean), and a comparison with other Mediterranean regions. Fournal of Natural History 39, 47-70.

Bartoli, P., Morand, S., Ruitort, J. J. and Combes, C. (2000). Acquisition of parasites correlated with social rank and behavioural changes in a fish species. Fournal of Helminthology 74, 289-293.

Bauchot, M. L. and Hureau, J. C. (1986). Sparidae. In Fishes of the North-Eastern Atlantic and the Mediterranean. Vol. II (ed. Whitehead, P. J. P., Bauchot, M.-L., Hureau, J.-C., Nielsen, J. and Tortonese, E.), pp. 883-907. Unesco, Paris.

Bell, J. D. and Harmelin-Vivien, M. I. (1983). Fish fauna of French Mediterranean Posidonia oceanica seagrass meadows. 2. Feeding habits. Tethys 11, 1-14.

Boyra, A., Sanchez-Jerez, P., Tuya, F., Espino, F. and Haroun, R. (2004). Attraction of wild coastal fishes to an Atlantic subtropical cage fish farm, Gran Canaria, Canary Islands. Environmental Biology of Fishes 70, 393-401.

Breck, J. E. (1993). Foraging theory and piscivorous fish: are forage fish just big zooplankton? Transactions of the American Fisheries Society 122, 902-911.

Bush, A. O., Lafferty, K. D., Lotz, J. M. and Shostak, A. W. (1997). Parasitology meets ecology in its own terms: Margolis et al. revisited. Fournal of Parasitology 83, 575-583.

Castro, J. J. and Hernández-García, V. (1995). Ontogenetic changes in mouth structures, foraging behaviour and habitat use of Scomber japonicus and Illex coindetii. Scientia Marina 59, 347-355.
Cushing, D. H. (1976). Biology of fishes in the pelagic community. In The Ecology of the Seas (ed. Cushing, D. H. and Walsh, J. J.), pp. 317-340. Blackwell, Oxford.

Dempster, T., Sanchez-Jerez, P., Bayle-Sempere, J. T., Giménez-Casalduero, $F$. and Valle, $C$. (2002). Attraction of wild fish to sea-cage fish in the south-western Mediterranean Sea: spatial and short-term temporal variability. Marine Ecology Progress Series 242, 237-252.

Dogiel, V. A., Petrushevski, G. K. and Polyanski, Y. I. (1958). Parasitology of Fishes. Oliver and Boyd, London (Translated from Russian by Z. Kabata, 1961).

Fernández, I., Moyano, F. J., Díaz, M. and Martínez, T. (2001). Characterisation of $\alpha$-amilase activity in five species of Mediterranean sparid fishes (Sparidae, Teleostei). Fournal of Experimental Marine Biology and Ecology 262, 1-12.

Froese, R. and Pauly, D. (Eds) (2007). FishBase. World Wide Web electronic publication. www.fishbase.org, version (04/2007).

Guégan, J. F. and Hugueny, B. (1994). A nested parasite species subset pattern in tropical fish: host as major determinant of parasite infracommunity structure. Oecologia 100, 184-189.

Janovy, J., Jr. Clopton, R. E., Clopton, D. A., Snyder, S. D., Efting, A. and Krebs, L. (1995). Species density distributions as null models for ecologically significant interactions of parasite species in an assemblage. Ecological Modelling 77, 189-196.

Johnson, M. W., Nelson, P. A. and Dock, T. A. (2004). Structuring mechanisms of yellow perch (Perca flavescens) parasite communities: host age, diet, and local factors. Canadian Fournal of Zoology 82, 1291-1301.

Jousson, O. and Bartoli, P. (1999). The life-cycle of three species of the Mesometridae (Digenea) with comments on the taxonomic status of this family. Systematic Parasitology 44, 217-228.

Jukic, S. (1972). Nutrition of the hake (Merluccius merluccius), bogue (Boops boops), striped mullet (Mullus barbatus) and pandora (Pagellus erythrinus) in the Bay of Kastela. Acta Adriatica 14, 3-40.

Karpouzi, V. S. and Stergiou, K. I. (2003). The relationship between mouth size and shape and body length for 18 species of marine fishes and their trophic implications. Fournal of Fish Biology 62, 1353-1365.

Kennedy, C. R. (1990). Helminth communities in freshwater fish: structured communities or stochastic assemblages? In Parasite Communities: Patterns and Processes (ed. Esch, G. W., Bush, A. O. and Aho, J. M.), pp. 130-156. Chapman and Hall, London.

Kennedy, C. R., Bush, A. O. and Aho, J. M. (1986). Patterns in helminth communities: why are birds and fish different? Parasitology 93, 205-215.

Linde, M., Palmer, M. and Gómez-Zurita, J. (2004). Differential correlates of diet and phylogeny on the shape of the premaxilla and anterior tooth in sparid fishes (Perciformes: Sparidae). Fournal of Evolutionary Biology 17, 941-952.

Lo, C. M., Morand, S. and Galzin, R. (1998). Parasite diversity/host age relationship in three coral-reef fishes from French Polynesia. International Fournal for Parasitology 28, 1695-1708. 
Luque, J. L., Mouillot, D. and Poulin, R. (2004). Parasite biodiversity and its determinants in coastal marine teleost fishes of Brazil. Parasitology 128, 671-682.

MacPherson, E. and Duarte, C. M. (1991). Bathymetric trends in demersal fish size: is there a general relationship? Marine Ecology Progress Series 71, 103-112.

Magnhagen, C. and Heibo, E. (2001). Gape size allometry in pike reflects variation between lakes in prey availability and relative body depth. Functional Ecology 15, 754-762.

Muñoz, G., Grutter, A. S. and Cribb, T. H. (2006). Endoparasite communities of five fish species (Labridae: Chelininae) from Lizard Island: how important is the ecology and phylogeny of the hosts. Parasitology $\mathbf{1 3 2}$, 363-374.

Pérez-del Olmo, A., Fernández, M., Gibson, D. I., Raga, J. A. and Kostadinova, A. (2007a).

Descriptions of some unusual digeneans from Boops boops L. (Sparidae) and a complete checklist of its metazoan parasites. Systematic Parasitology 66, 137-158.

Pérez-del Olmo, A., Raga, J. A., Kostadinova, A. and Fernández, M. $(2007 b)$. Parasite communities in Boops boops (L.) (Sparidae) after the Prestige oil-spill: detectable alterations. Marine Pollution Bulletin 54, 266-276.

Poulin, R. (2000). Variation in the intraspecific relationship between fish length and intensity of parasite infection: biological and statistical causes. Fournal of Fish Biology 56, 123-137.

Poulin, R. and Guégan, J. F. (2000). Nestedness, anti-nestedness, and the relationship between prevalence and intensity in ectoparasite assemblages of marine fish: a spatial model of species coexistence. International Fournal for Parasitology 30, 1147-1152.

Poulin, R. and Valtonen, E. T. (2001). Nested assemblages resulting from host size variation: the case of endoparasite communities in fish hosts. International Fournal for Parasitology 31, 1194-1204.

Power, A. M., Balbuena, J. A. and Raga, J. A. (2005). Parasite infracommunities as predictors of harvest location of bogue (Boops boops L.) : a pilot study using statistical classifiers. Fisheries Research 72 , 229-239.

Renaud, F., Romestand, B. and Trilles, J. P. (1980). Faunistique et écologie des métazoaires parasites de Boops boops Linnaeus (1758) (Téléostéen Sparidae) dans le Golfe du Lion. Annales de Parasitologie Humaine et Comparée 55, 467-476.
Rohde, K. (1989). Simple ecological systems, simple solutions to complex problems. Evolutionary Theory $\mathbf{8}$, 305-350.

Rohde, K., Worthen, W. B., Heap, M., Hugueny, B. and Guégan, J. F. (1998). Nestedness in assemblages of metazoan ecto-and endoparasites of marine fish. International Fournal for Parasitology 28, 543-549.

Ruitton, S., Verlaque, M. and Boudouresque, C. F. (2005). Seasonal changes of the introduced Caulerpa racemosa var. cylindracea (Caulerpales, Chlorophyta) at the northwest limit of its Mediterranean range. Aquatic Botany 82, 55-70.

Saad-Fares, A. and Combes, C. (1992). Abundance/ host size relationship in a fish trematode community. Fournal of Helminthology 66, 187-192.

Sánchez, P., Demestre, M. and Martín, P. (2004). Characterisation of the discards generated by bottom trawling in the northwestern Mediterranean. Fisheries Research 67, 71-80.

Sasal, P., Niquil, N. and Bartoli, P. (1999). Community structure of digenean parasites of sparid and labrid fishes of the Mediterranean sea: a new approach. Parasitology 119, 635-648.

Stergiou, K. I. and Karpouzi, V. S. (2002). Feeding habits and trophic levels of Mediterranean fish. Reviews in Fish Biology and Fisheries 11, 217-254.

Timi, J. A. and Poulin, R. (2003). Parasite community structure within and across host populations of a marine pelagic fish: how repeatable is it? International Fournal for Parasitology 33, 1353-1362.

Valle, C., Bayle-Sempere, J. T. and Ramos-Esplá, A. A. (2003). Aproximación multiescalar al estudio de la ictiofauna del litoral rocoso de Ceuta (España). Boletín Instituto Español de Oceanografía 19, 419-431.

Vidal-Martinez, V. M. and Poulin, R. (2003). Spatial and temporal repeatability in parasite community structure of tropical fish hosts. Parasitology 127, 387-398.

Vidal-Martinez, V. M., Kennedy, C. R. and Aguirre-Macedo, M. L. (1998). The structuring process of the macroparasite community of an experimental population of Cichlasoma urophthalmus through time. Fournal of Helminthology 72, 199-207.

Williams, H. H. and MacKenzie, K. (2003). Marine parasites as pollution indicators: an update. Parasitology 126, S27-S41.

Zelmer, D. A. and Arai, H. P. (2004). Development of nestedness: Host biology as a community process in parasite infracommunities of yellow perch (Perca flavescens (Mitchill)) from Garner Lake, Alberta. Fournal of Parasitology 90, 435-436. 